\title{
CFD Simulation of Upward Flame Spread over Fuel Surface
}

\author{
ZHENGHUA YAN and GÖRAN HOLMSTEDT \\ Department of Fire Safety Engineering \\ Lund University \\ PO Box 118, S-221 00, Lund, Sweden
}

\begin{abstract}
Two-dimensional upward flame spread and subsequent steady burning of a vertical PMMA surface was studied using CFD methodology. Both the turbulent combustion of the gas phase and the pyrolysis of the solid fuel were numerically simulated. The transpired wall function was used to calculate the convection heat transfer with the blowing effect considered. Radiation was considered by using the discrete transfer method. A fast narrowband computer model, FASTNB, which predicts the radiation properties of the combustion products in a general, non-isothermal and non-homogeneous combustion environment, was implemented for the solution of the radiation equation along every ray. An efficient, simple and practical pyrolysis model was adopted to describe the pyrolysis of the solid fuel. The sensitivity of the prediction to grid, time step interval and ray number was analysed. The calculated flame spread velocity, heat fluxes, and the steady burning rate, etc. were analysed and compared with experimental measurements. Good agreement was obtained.
\end{abstract}

KEYWORDS: CFD simulation, Heat transfer, Pyrolysis, Flame spread, Steady burning

\section{INTRODUCTION}

Upward flame spread is a typical process of fire growth. A number of experimental and theoretical investigations have been conducted [1-5] in this area. In [1], the small scale upward laminar flame spread was analysed without considering the effect of flame radiation. 
The others [2-5] studied the upward turbulent flame spread. In the cases of turbulent flame spread, some experiments have been carried out to measure temperature, heat flux and the turbulent upward flame spread velocity. By introducing considerable simplifications and assumptions, and using the correlation method, some empirical or semi-empirical formulas have also been derived to predict the upward flame spread velocity.

Unfortunately, flame spread over a solid fuel surface is very complex. A number of complex physical and chemical sub-processes are involved, including: transient heating and pyrolysis of the solid fuel, gas flow and combustion which are usually turbulent as long as the scale is large enough, and heat transfer via convection and radiation, etc. The situation is further complicated by the facts that the thermal properties of solid fuel are usually temperature dependent, the radiation properties of the combustion products are highly non-grey, and the blowing effect of the pyrolysis gas may cause considerable blockage to the heat transfer, etc. All the sub-processes involved are complex and interactive. A generally applicable prediction tool should be able to take the sub-processes involved into consideration. Due to the complexity of flame spread, no general, accurate analytical solution exists.

As an important engineering research tool, CFD technology has made a significant contribution since it emerged. With the rapid growth of computer power and progress in the fundamental understanding of sub-processes in fires, it is expected that CFD will play a more important role, and ultimately be the most satisfactory treatment for flame spread and fire growth. Very recently, Zhenghua Yan and Göran Holmstedt [6] made an attempt to simulate room corner fire growth on wall lining material using CFD methodology. In their study, extensive comparisons were made between predictions and experimental measurements and the agreement was found to be both satisfactory and promising.

This paper presents further progress in the area of CFD predictions of fire spread. In this study, upward flame spread on PMMA was simulated using CFD. An efficient pyrolysis model was adopted to describe the pyrolysis of the solid fuel. A fast narrow-band model was implemented for the radiation calculation and a transpired wall function was used to predict the convection heat transfer between the gas and solid fuel, with the blowing effect considered. The results are compared with experimental measurements performed by Orloff et al [2].

\section{THEORETICAL MODELS}

The CFD simulation of the fire spread is based on the numerical solution of a set of mathematical equations, with each of the fire sub-processes considered represented by a related theoretical model. Due to limited space, the theoretical models are only presented very briefly here. Readers are referred to the references cited below for details.

\section{Fluid Dynamics And Combustion Model}


The turbulent flow in a fire is controlled by fluid dynamics, which is mainly represented by a set of partial differential governing equations [7,8]. The standard $k-\varepsilon$ model, adapted to incorporate the buoyancy effect [9], was used to study the turbulence characteristics of the gas flow, whilst further fundamental investigation on the turbulence model for the buoyancy-driven flow would be desirable.

In this study, combustion was approximated by an one-step chemical reaction, in which complete oxidation is assumed when sufficient oxygen is available, and the local reaction rate is determined by the eddy dissipation combustion model to be the slowest of the turbulence dissipation rates of either fuel or oxygen [10].

\section{Consideration of Soot}

Soot can contribute significantly to the radiation in a fire. In order to calculate the radiation accurately, soot must be considered. Unfortunately, sooting is a very complex process and no very good model is currently available for soot prediction in the combustion of solid fuel, although some significant progress [11] in the soot modeling has been made in the recent years. In this study, as an approximation, soot was considered by assuming a constant soot conversion factor, $2 \%$, chosen with reference to experimental measurements $[12,13]$. The soot formation rate was simply assumed to be proportional to the fuel supply rate. No oxidation was considered. In this particular study, the contribution of soot was assumed to be the radiation only.

\section{The Radiation Model}

Radiation is an important heat transfer mechanism in a fire. Under many circumstances, heat transfer is dominated by radiation. In this study, the discrete transfer method was adopted to calculate the radiation, with a fast narrow-band model, FASTNB, incorporated to predict the radiation properties of the combustion products.

The discrete transfer method and radiation equation. DT is one of the most popular methods used in the numerical calculation of radiation. This method solves the radiation equation along a discrete set of directions (rays) from every element of the boundary surface. See [14] for details.

For a non-scattering medium in local thermodynamic equilibrium, the differential equation of the spectral radiation can be written $[15,16]$,

$$
\frac{\partial I_{w, s}}{\partial s}=-k_{w, s} I_{w, s}+k_{w, s} I_{w, s}^{0}
$$

where the superscript 0 denotes black body and $w$ the wave number. 
Assuming the origin of the path to be located at point 0 , the total radiation intensity can be given by

$I=\int_{0}^{\infty} I_{w, s} d w=\int_{0}^{\infty} I_{w, 0} \tau_{w, 0 \rightarrow s} d w+\int_{0}^{\infty} \int_{0}^{s} I_{w, s^{\prime}}^{0} \frac{\partial \tau_{w, s^{\prime} \rightarrow s}}{\partial s^{\prime}} d s^{\prime} d w$

where $\tau_{w, s^{\prime} \rightarrow s}$ is the spectral transmissivity of the gas volume between $s$ and $s^{\prime}$.

The narrow-band model. The solution of the radiation transfer equation relies on the evaluation of the radiation properties of the combustion products. In this study, the radiation properties are provided by the narrow-band model $[15,17,18]$, which is based on spectral calculations. The narrow-band model is applied to each individual species to calculate the spectral optical depth. The contributions of all the species to the total spectral optical depth are assumed to be additive.

For a general gas path, the overall optical depth is given by:

$X=-\ln \tau=X^{*}\left\{1-\left[\left(1-\left(\frac{X_{c}}{X^{*}}\right)^{2}\right)^{-2}+\left(1-\left(\frac{X_{d}}{X^{*}}\right)^{2}\right)^{-2}-1\right]^{-0.5}\right\}^{0.5}$

where $X^{*}$ is the optical depth in the weak line limit, and $X_{c}$ and $X_{d}$ are optical depths of collision and Doppler lines respectively.

The spectral calculation offers good accuracy and generality, but at a high price. The computation time is of great concern, especially when incorporated into CFD to study turbulent reacting flows. The narrow-band computation speed was improved significantly in a recent study [18].

\section{Transpired Wall Function}

In this study, the solid fuel was assumed to be a non-slip boundary and the wall function was used to calculate the convective heat transfer. In order to consider the blowing effect of the pyrolysed gas, a transpired wall function was adopted when the solid fuel starts to pyrolyse.

Due to limited space, some important formulas are simply presented below. Readers are referred to [19] and [20] for details.

For a laminar flow boundary layer, we have

$$
\begin{aligned}
& u_{+}=\left(\exp \left(m_{+} y_{+}\right)-1\right) / m_{+} \\
& \varphi_{+}=\left(\exp \left(\sigma_{\varphi} m_{+} y_{+}\right)-1\right) / m_{+}
\end{aligned}
$$

where $\varphi$ represents both mass concentration $m_{j}$ and enthalpy $h$, and $\sigma_{\varphi}$ is the Schmidt number when $\varphi=m_{j}$ and laminar Prandtl number when $\varphi=h$.

For a turbulent flow boundary layer, the following relations exist 


$$
\begin{aligned}
& u_{+}=\kappa^{-1} \ln \left(E y_{+}\right)+(2 \kappa)^{-2} m_{+}\left[\ln \left(E y_{+}\right)\right]^{2} \\
& \varphi_{+}=\left\{\exp \left[\sigma_{t}\left(\ln \left(1+m_{+} u_{+}\right)+m_{+} P\right)\right]-1\right\} / m_{+}
\end{aligned}
$$

where $E$ and $P$ are integration constants [19].

At the limit as $m_{+} \rightarrow 0$, equations (4)-(7) will be reduced to $u_{+}=y_{+}, \varphi_{+}=\sigma_{\varphi} y_{+}$, $u_{+}=\kappa^{-1} \ln \left(E y_{+}\right)$and $\varphi_{+}=\sigma_{t}\left(u_{+}+P\right)$, respectively.

During the calculation, turbulent boundary formulas were used if $y_{+}>11.63$, otherwise the laminar boundary formulas were employed.

\section{The Pyrolysis Model}

The solid fuel is heated by exposure to heat sources and then begins to pyrolyse as the temperature reaches its pyrolysis temperature. An efficient and simple pyrolysis model [6] was incorporated into CFD to describe the burning of the solid material. It has great flexibility and can easily be used in the complex cases such as those with transient incident heat flux and temperature-dependent material properties. It is generally applicable to charring and non-charring material [6]. This model is based on the numerical solution of the following equation,

$$
\frac{\partial(\rho H)}{\partial}+m^{\prime \prime \prime}\left(H_{p y}+H\right)+\frac{\partial\left[m^{\prime \prime}\left(H_{G, T}-H_{G, T_{p}}\right)\right]}{\partial x}=\frac{\partial}{\partial x}\left(k \frac{\partial T}{\partial x}\right)
$$

where $m^{\prime \prime \prime}=-\frac{\partial \rho}{\partial t}=\frac{\partial m^{\prime \prime}}{\partial x} \geq 0$ and represents the mass loss rate of the pyrolysing material per unit volume. The third term is the energy required to heat the vaporised gas as it flows to the solid surface. This term will be zero for non-charring material. $H_{p y}$ is the heat of reaction of the pyrolysis process.

In this pyrolysis model, different grades of mesh were used for temperature and mass loss calculations. The relatively coarse thermal mesh was refined for the mass loss calculation. This methodology minimizes the storage and computation time requirements without loosing the physical basis. This pyrolysis model was used to simulate the Cone test of PMMA, and excellent agreement was obtained [6].

\section{THE SIMULATED PROBLEM}

The configuration of the simulated problem is shown in Fig. 1. The PMMA slab is $4.5 \mathrm{~cm}$ thick and $114 \mathrm{~cm}$ high. A small propane gas burner is located at the bottom of the PMMA slab as an ignition source. The output of the burner is $10.0 \mathrm{~kW} / \mathrm{m}$. Since the burner output is 
quite small, its effect on the flame spread, especially in the later stages, is negligible. The flame spread process is mainly controlled by the flame of the PMMA itself.

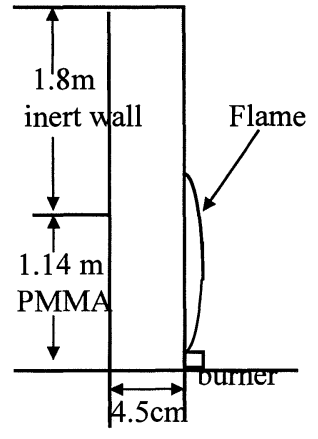

Figure 1 Configuration of the problem

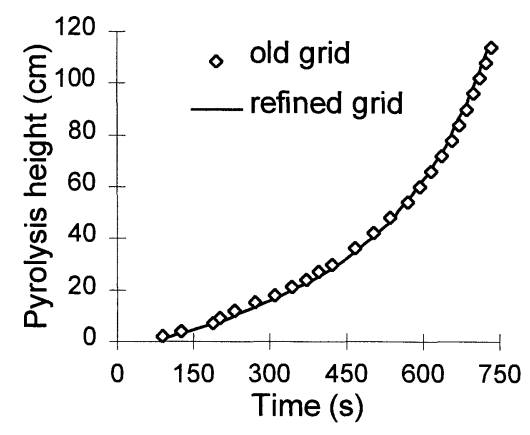

Figure 2 Results of grid dependence study

The flow of this problem is essentially parabolic, i.e. the down stream flow characteristics are controlled mainly by the up stream flow. However, the radiation from the down stream to the up stream can not be neglected. Therefore, the computation domain was extended far enough (tested in numerical experiments) to calculate the radiation correctly.

The thermal properties of PMMA were taken directly from the literature $[2,22,23]$ : $\rho_{0}=1190 \mathrm{~kg} / \mathrm{m}^{3}, k=2.49 \times 10^{-7} \mathrm{~T}+1.18 \times 10^{-4} \mathrm{~kW} / \mathrm{m} \cdot \mathrm{K}, \quad c_{p}=2.374 \times 10^{-3} \mathrm{~T}+1.1 \mathrm{~J} / \mathrm{g} \cdot \mathrm{K}$, $T_{p}=363^{\circ} \mathrm{C}, H_{c}=24.88 \mathrm{~kJ} / \mathrm{g}$.

From the heat of the gasification of thermally thick PMMA at steady state, which is $1.61 \mathrm{~kJ} / \mathrm{g}$ [2], $H_{p y}$ can be calculated from [6]

$H_{p y}=H_{g}-\int_{T_{0}}^{T_{p}} c_{p} d T=H_{g}-\int_{T_{0}}^{T_{p}}\left(2.374 \times 10^{-3} T+1.1\right) d T \approx 0.9 \mathrm{~kJ} / \mathrm{g}$

The average values of $k$ and $c_{p}$ over the temperature range from the ambient to the pyrolysis are $2.34 \mathrm{~W} / \mathrm{mk}$ and $2.2 \mathrm{~J} / \mathrm{gk}$ respectively, which are in close agreement with the data of Orloff [2].

The configuration of the simulated problem is comparable with the setup used by Orloff et al. In their experiment, two water-cooled side walls were used to ensure truly twodimensional flame spread and $3 \mathrm{cc}$ acetone was used to ignite a PMMA slab of $41 \mathrm{~cm}$ wide and $157 \mathrm{~cm}$ high. In the simulation, for simplicity, an ideal two-dimensional flame spread was studied and a propane gas burner was used as the igniter. The height of PMMA was reduced to $114 \mathrm{~cm}$ with a test computation carried out to study the effect of the PMMA height, which is mainly on the steady burning. At the steady burning state, the burning rate and heat fluxes were found to increase by about $10 \%$ when the height of the PMMA slab was increased from $114 \mathrm{~cm}$ to $157 \mathrm{~cm}$. 


\section{SENSITIVITY ANALYSIS OF THE SOLUTION}

Numerical experiments were carried out to analyse the sensitivity of the solution to the mesh size, DT ray number and time step, etc. Since the narrow-band calculation of the radiation is relatively time consuming, during the sensitivity studies, it was replaced by a simple integral method [6, 24]. A test run was performed to study the difference in results from the integral method compared with the narrow-band model.

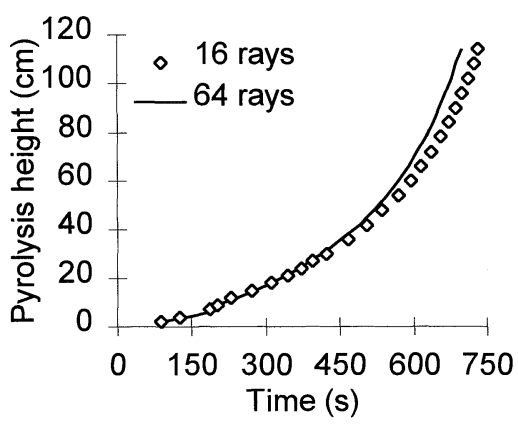

Figure 3 Effect of the ray number

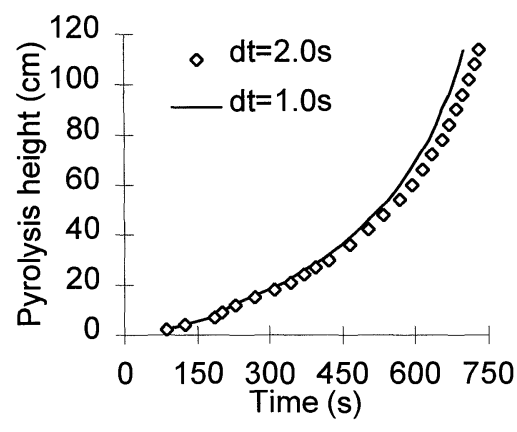

Figure 4 Effect of the time step

A non-uniform grid was used for the gas phase, with much denser mesh applied to the area close to the wall and the lower part (PMMA zone) of the computation domain. The results with two different grids $(36 \times 26$ and $60 \times 30)$ are compared in Fig. 2 , in which only minor difference can be seen. This indicates that the $36 \times 26$ grid is fine enough for this particular calculation.

The effects of DT ray number and time step are shown in Fig. 3 and Fig. 4 respectively. These two figures show that a DT ray number of 16 and time step of 2.0 seconds are acceptable in this study.

The sensitivity of the solution to the soot conversion factor was also analysed by reducing the soot conversion factor by $50 \%$, as shown in Fig. 5 . The soot emissivity is apparently reduced. Therefore, the radiation flux will be lower and the flame spread will decelerate. However, Fig. 5 shows the difference in results is surprisingly small. This can be explained as follows.

The total heat flux is the sum of the radiation flux from the soot and gases (mainly $\mathrm{CO}_{2}$ and $\mathrm{H}_{2} \mathrm{O}$ ), and the convection heat flux. Therefore, the radiation from soot is about $50 \%$ of the total heat flux, even if the radiation is the dominant heat transfer mechanism $(70 \%$, for example) and the radiation comes mainly from soot (again $70 \%$, for example). In the following analysis, since the radiation is assumed to be dominated by soot, a simplication is made by decoupling the soot radiation from the gas radiation. Approximately, the spectral soot absorption-emission coefficient is inversely proportional to wavelength: $k_{\lambda}=B f_{v} / \lambda$, where $B$ is a constant and $f_{v}$ is the soot volume fraction. The spectral soot emissivity can 
be calculated from $\varepsilon_{\lambda}=1-\exp \left(-k_{\lambda} l\right)=1-\exp \left(-B^{*} f_{v}\right)$, where $B^{*}=B l / \lambda$ and $l$ is the pathlength. It can be easily proven that the ratio $\left[1-\exp \left(-0.5 B^{*} f_{v}\right)\right] /\left[1-\exp \left(-B^{*} f_{v}\right)\right]$ is always higher than 0.5 and increases monotonically with $f_{v}$. Thus, the difference in total heat flux can be, at most, $25 \%$ if the soot radiation accounts for $50 \%$ of the total heat flux. Furthermore, since the soot radiation is reduced, the gas temperature will be higher and consequently the black body emission and the convection will be somewhat increased. This implies that some compensation will be made for the soot radiation reduction. Therefore, the final difference in total heat flux and the flame spread which is dependent on the total heat flux, could be small. However, this simple analysis does not mean that soot radiation is not important. The total heat flux will be greatly reduced in the absence of soot.

The radiation fluxes calculated using the narrow-band model and the simple integral method are compared in Fig. 6, which shows that the simpler and faster integral method can be used for the approximate calculations. However, it should be pointed out that the difference of radiation fluxes is dependent on the radiating path length and the profiles of the temperature and concentrations of the radiating species along the path. A large deviation may arise if the simple integral method is applied to a long path with low soot loading and steep profiles.

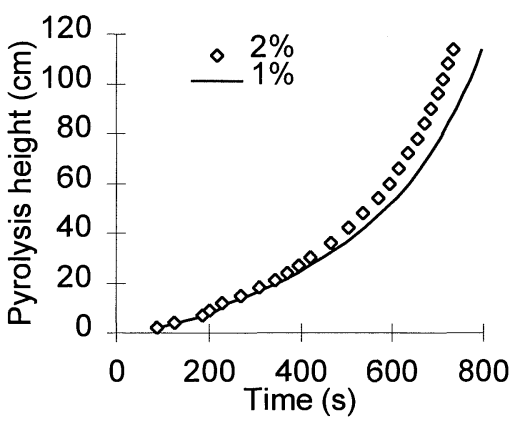

Figure 5 Effect of soot conversion factor

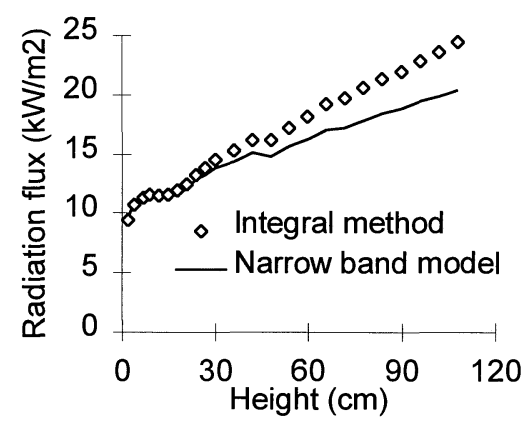

Figure 6 Flame radiation flux to surface

\section{RESULTS AND DISCUSSION}

Using CFD, comprehensive insight can be obtained into the flame spread velocity, steady burning rate, heat flux and temperature distribution, etc. In this paper, some representative results are presented and compared with the experimental measurements of Orloff et al [2].

\section{Vertical Flame Spread Velocity}

Fig. 7 shows the comparison of the predicted vertical flame spread velocity with experimental measurements. Both prediction and measurements indicate that the upward 
spread velocity is approximately proportional to the height. Since flame spread velocity is the time derivative of the pyrolysis height, it increases exponentially with time, as shown in Fig. 8. The agreement between prediction and experiment is quite good. The prediction is generally within the uncertainties of the measurement. The oscillation which occurred in the prediction would disappear gradually as the resolution of space and time is increased.

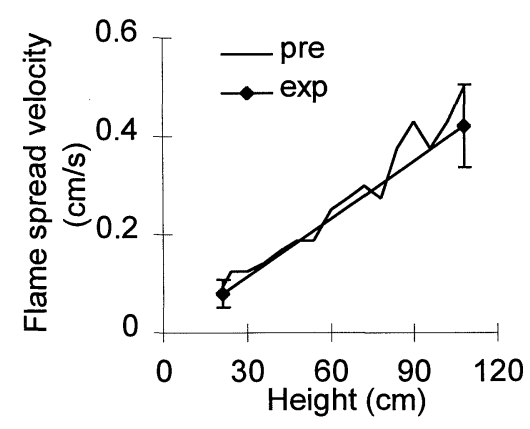

Figure 7 Flame spread velocity vs height

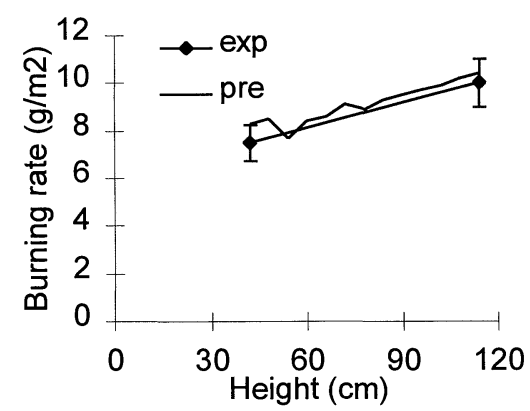

Figure 9 Steady burning rate vs height

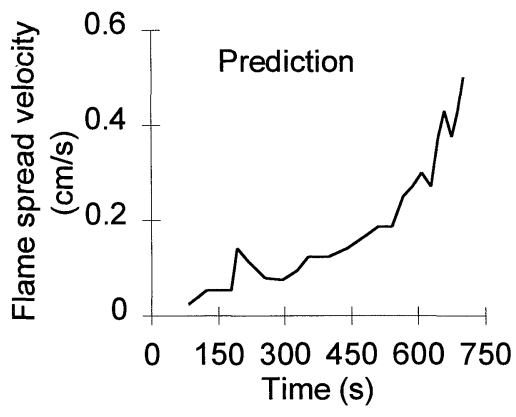

Figure 8 Flame spread velocity vs time

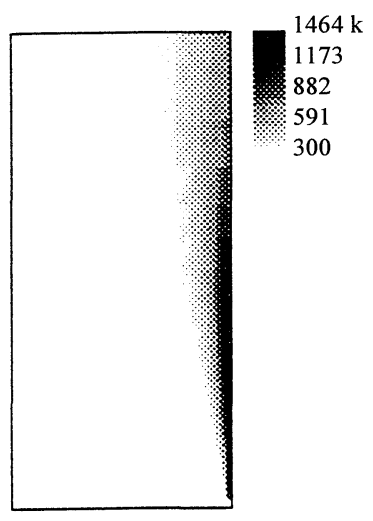

Figure 10 Gas temperature distribution

\section{Steady Burning Rate}

The simulation was continued until a quasi-steady burning state had been reached. Fig. 9 shows the variation of the predicted and measured burning rates with height. In general, the prediction agrees well with experimental results. Both prediction and experiment show that the steady burning rate increases continuously with the height. This increase is found to be attributed to the increase in the radiation flux (see 'Heat Flux' section) resulting from the growth of the flame and hot gas layer. 


\section{Heat Flux}

Heat flux is critical to the flame spread. In the experiments conducted by Orloff et al., the solid surface radiant flux was measured with a thermopile radiometer, and the combined outward perpendicular flame and solid radiant fluxes were measured with a nitrogen-purged 'telescopic' radiometer. By introducing some assumptions, the radiant flux from the flame to the center line of the surface was calculated, and the convection flux was then inferred from the surface energy balance [2]. Apparently, there are some uncertainties with their calculated and inferred heat fluxes.

The calculated and measured heat fluxes in the steady-state burning are compared in Table 1 . The agreement is reasonably good. Both prediction and experiment demonstrate that the radiation flux increases significantly with height and that radiation is the dominant heat transfer mechanism at high locations, while the convection flux is characteristically constant. The increase in radiation flux is mainly due to the growth of flame and hot gas layer shown in Fig. 10. Since the increasing mass transfer causes more blockage to convection transfer, the convection heat flux decreases slightly with height.

TABLE 1. Comparison of heat fluxes $(\mathrm{kW} / \mathrm{m} 2)$

Note: conv. $=$ convection, $\mathrm{rad}=$ radiation, pre=prediction, $\exp =$ inferred from experiment, trans=transpired wall function, non-trans $=$ non-transpired wall function

\begin{tabular}{|l|l|c|c|c|c|c|c|}
\hline $\begin{array}{c}\text { Height } \\
(\mathrm{cm})\end{array}$ & $\begin{array}{c}\text { Conv } \\
\text { (exp) }\end{array}$ & $\begin{array}{c}\text { Conv } \\
\text { (pre, trans })\end{array}$ & $\begin{array}{c}\text { Rad } \\
\text { (exp) }\end{array}$ & $\begin{array}{c}\text { Rad } \\
\text { (pre) }\end{array}$ & $\begin{array}{c}\text { Total flux } \\
\text { (exp) }\end{array}$ & $\begin{array}{c}\text { Total flux } \\
\text { (pre) }\end{array}$ & $\begin{array}{c}\text { Conv } \\
\text { (pre, non-trans) }\end{array}$ \\
\hline 38.1 & 6.5 & 11.4 & 13.5 & 13.8 & 20.0 & 25.2 & 14.0 \\
50.8 & 6.1 & 10.9 & 14.7 & 15.1 & 20.8 & 26.0 & 13.6 \\
76.2 & 4.1 & 10.4 & 17.9 & 17.0 & 22.0 & 27.4 & 13.1 \\
101 & 4.9 & 9.8 & 19.3 & 18.9 & 24.2 & 28.7 & 13.3 \\
\hline
\end{tabular}

Table 1 also shows that the predicted convection heat fluxes are significantly higher than the inferred data. One reason for this discrepancy might be that the water-cooled side walls used in the experiment were not considered in the simulation. Another, perhaps more likely, reason could be the uncertainties in the inferred data. As stated in a similar experiment [25], the inferred convection flux could be lower than the actual value. The inaccuracy of the CFD theoretical models including the turbulence model, combustion model and wall function could also be responsible. Since the heat flux can be affected by all these interactive models, it is difficult to evaluate the models separately.

Listed in the last column is the convection heat flux calculated using non-transpired wall function. Comparing this column with column 3 clearly shows the convection blockage caused by the mass transfer. 


\section{CONCLUSIONS}

The upward flame spread over solid fuel surface has been successfully simulated using the CFD method. The flame spread velocity, heat fluxes and steady burning rates were calculated and found agree well with experimental measurements. This indicates that flame spread can be expected to be simulated by using CFD, and provides considerable encouragement for future research in this area.

A fast narrow-band computer model was incorporated into CFD to calculate the radiation properties of the combustion products in a general non-homogeneous non-isothermal combustion environment. With the computation speed significantly improved, the narrow band model could be used in the CFD calculations.

Although the overall flame spread characteristics were reproduced quite well, there might be considerable deviations regarding the details of the turbulent fluid dynamics and turbulent combustion, etc. As is well recognised, there are still many deficiencies in the computer modeling of turbulent buoyancy-driven reacting flows. Further improvements are necessary, especially in the areas related to the CFD technology, such as turbulence, turbulent combustion and soot models, and wall function. The predictions can be expected to be improved if one can afford to use more advanced CFD models.

Since CFD simulation of flame spread is a comprehensive and, to some extent, fundamental study, once it is well established, it can be used as a generally applicable and important prediction tool for fire growth, which may prove very valuable in fire safety.

\section{REFERENCE}

1. Fernandez-Pello, A. C., "A theoretical model for the upward laminar spread of flames over vertical surfaces", Combustion and Flame, 35, pp. 135, 1978

2. Orloff, L., deRis, J., and Markstein, G. H., "Upward turbulent fire spread and burning of fuel surface", 15th Symposium (International) on Combustion, pp. 167, 1979

3. Saito, K., Quintiere, J. G., and Williams, F. A., "Upward turbulent flame spread", Proceeding of First International Symposium on Fire Safety Science, pp. 75, 1985

4. Hasemi, Y., "Thermal modeling of upward wall flame spread", Proceeding of First International Symposium on Fire Safety Science, pp. 87, 1985

5. Hasemi, Y., Yoshida, M., Nohara, A., and Nakabayashi, T., "Unsteady-state upward flame spreading velocity along vertical combustible solid and influence of external radiation on the flame spread", Proceeding of Third International Symposium on Fire Safety Science, pp. 197, 1991

6. Yan Z. and Holmstedt G., "CFD and Experimental Studies of Room Fire Growth on Wall Lining Materials", Fire Safety Journal, in press

7. Cox G. \& Kumar S., "Field Modeling of Fire in Forced Ventilated Enclosures", Comb. and Tech., 52 (1987) 7-23 
8. Kumar S. \& Cox G., "Mathematical Modeling of Fires in Road Tunnels", $\underline{\text { th }}$ International Symposium on the Aerodynamics and Ventilation of Vehicle Tunnels, 1985, pp. 61-76

9. Rodi W., "Turbulence Models and Their Application in Hydraulics - A State of The Art Review", SBF Report 80/T/125, University of Karlsruhe, 1980

10. Magnussen B. F. \& Hjertager B. H., "On Mathematical Modeling of Turbulent Combustion with Special Emphasis on Soot Formation and Combustion", 16th Symp. (Int.) on Combustion. The Combustion Institute, 1976, pp. 719-729

11. Bockhorn H. (Ed.), Soot Formation in Combustion - Mechanisms and Models. SpringerVerlag, 1994

12. Mulholland G. W., "Smoke Production and Properties", the SFPE Handbook of Fire Protection Engineering, Second Edition, Chapter 2-15, 1995

13. Tewarson A., "Generation of Heat and Chemical Compounds in Fires", the SFPE Handbook of Fire Protection Engineering, Second Edition, Chapter 3-4, 1995

14. Lockwood F. C. \& Shah N. G., "A New Radiation Solution Method for Incorporation in General Combustion Prediction Procedures", 18th Symp. (Int.) on Combustion, The Combustion Institute, 1981, pp. 1405-1414

15. Ludwig C., Malkmus W., Reardon J. and Thomson J., Handbook of Infrared Radiation from Combustion Gases, NASA SP-3080, 1973

16. Siegel R. and Howell J. R., Thermal Radiation Heat Transfer, Hemisphere Publishing Corp., Washington, pp. 683-689, 1992

17. Grosshandler W. L., "RADCAL: A Narrow-Band Model for Radiation Calculation in a Combustion Environment", NIST technical note 1402, 1993

18. Yan Z. and Holmstedt G., "A Fast Narrow Band Computer Model for Radiation Calculation", Numerical Heat Transfer, Part B: Fundamentals, in press

19. Patanker S. V. and Spalding D. B., Heat and Mass Transfer in Boundary Layers. 2nd edition, published by International Textbook Company Ltd., 1970

20. Spalding D. B., Genmix - A General Computer Program for Two - Dimensional Parabolic Phenomena, Pergamon press, 1977

21. Sibulkin M., "Heat of Gasification for Pyrolysis of Charring Materials", Fire Safety Science-Proceeding of the First International Symposium, pp. 391-400, 1985

22. Quintiere J. G. and Rhodes B., "Fire Growth Models for Materials", NIST-GCR-94-647, National Institute of Standards and Technology, 1994

23. Barbrauskas V. and Grayson S. J., Heat Release in Fires, Elsevier Applied Science, 1992

24. Modak A. T., "Radiation from Products of Combustion", Fire Research, 1 (1978/1979) 339-361

25. De Ris, J. and Orloff, L., "The Role of Buoyancy Direction and Radiation in Turbulent Diffusion Flames on Surfaces", 15th Symp. (Int.) on Combustion, The Combustion Institute, 1974, pp. 175-182 